\title{
A implantação de política pública para os resíduos sólidos urbanos recicláveis: o Coleta Palmas
}

\section{Fábia dos Santos Mello ${ }^{1}$ e Héber Rogério Gracio²}

\author{
${ }^{1}$ Universidade Federal do Tocantins. Programa de Pós-Graduação em Ciências do \\ Ambiente. Campus Universitário de Palmas. Quadra 109 Norte. Avenida NS 15. \\ Plano Diretor Norte. Palmas-TO, Brasil (CEP 77001-090). E-mail: \\ fabiaarq@gmail.com. \\ ${ }^{2}$ Universidade Federal do Tocantins. Campus Universitário de Palmas. Quadra 109 \\ Norte. Avenida NS 15. Plano Diretor Norte. Palmas-TO, Brasil (CEP 77001-090).
}

Resumo. A gestão dos resíduos sólidos urbanos caracteriza-se como um dos grandes problemas para as administrações públicas no Brasil, mesmo após a publicação da Lei no 12.305/2010, que instituiu a Política Nacional de Resíduos Sólidos (PNRS). Quando os resíduos sólidos urbanos recicláveis são o tema percebe-se o agravamento em se fazer cumprir e aplicar as leis. Isto se dá, muitas vezes, por insuficiência de recursos financeiros; carência de recursos humanos; falta de entrosamento e convergência de ideias dos vários departamentos. Este artigo trata da política pública de coleta seletiva, o Programa Coleta Palmas, que está em funcionamento desde 2017, por meio da modalidade Ponto de Entrega Voluntária (PEV) em Palmas, Tocantins. A metodologia se deu por meio de pesquisas bibliográficas para o levantamento das Leis e diretrizes relacionadas à coleta seletiva e reciclagem; houve a interação com as associações e a cooperativa parceiras na implantação da política pública; levantamento de documentos dos órgãos públicos sobre a gestão, geração, manejo e disposição final dos resíduos sólidos urbanos, incluindo informações do programa. Constatou-se que, apesar da coleta seletiva ter custos superiores à coleta convencional tem-se os ganhos socioambientais para as atuais e futuras gerações, extrapolando a avaliação econômica e transformando a realidade local.

Palavras-chave: Coleta seletiva; Políticas Públicas; Reciclagem.

Abstract. The implementation of the public policy for solid waste recyclable: The Palmas Collection. The management of urban solid waste is characterized as one of the biggest problems for public administrations in Brazil, even after the publication of Law 12.305/2010, which instituted the National Solid Waste Policy. The difficulty apply and enforcing the laws is aggravated when it comes to recyclable municipal solid waste. This is often due to insufficient financial resources, a shortage of human resources or a lack of convergence and convergence of ideas from the various departments beyond those involved that are necessary to implement a public policy. This article deals with the
Recebido

$20 / 09 / 2019$

Aceito

$27 / 12 / 2019$

Publicado

$31 / 12 / 2019$

Acesso aberto

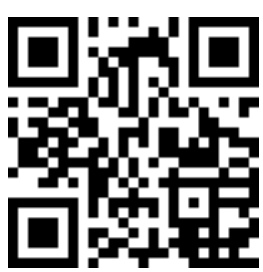

ORCII

(D) 0000-0001-7992-4473

Fábia dos Santos Mello

(D) 0000-0001-5380-2486 Héber Rogério Gracio 
public policy of selective collection - the Palmas Collection, which has been in operation since 2017, it works in modality PEV Voluntary Delivery Point in Palmas, Tocantins States, North Brazil. It is the result of a master's dissertation and the methodology was given through bibliographical research for the survey of Laws and guidelines related to selective collection and recycling; there was interaction with the associations and cooperative partners in the implementation of public policy; collection of documents from public agencies on the management, generation, management and final disposal of solid urban waste including program information. It was found that although the selective collection has higher costs than the conventional collection, the socio-environmental gains for current and future generations are extrapolated, and the governments in all spheres must practice public policies, thus meeting the request of the involved and transforming the local reality.

Keywords: Selective collection; Public policy; Recycling.

\section{Introdução}

Um dos grandes problemas que as cidades brasileiras enfrentam na atualidade é a geração de Resíduos Sólidos Urbanos (RSU), popularmente conhecidos como lixo. Estes, quando não são tratados, apresentam claras consequências e impactos na saúde pública, estando diretamente atrelados às doenças como a dengue, zika e chikungunya e tantos outros males que afligem as populações urbanas. Suas repercussões na infraestrutura das cidades também são claras e se tornam mais evidentes com as enxurradas, causadas por entupimento nos sistemas de macrodenagem, barramento de pequenos córregos que cortam áreas urbanas e outras tantas ocorrências observadas durante os períodos chuvosos. Ainda tendo em conta a infraestrutura urbana, deve-se também observar os impactos dos aterros sanitários, lixões e outros espaços urbanos que são afetados pelo acúmulo de lixo.

Os resíduos sólidos urbanos também compõem a problemática econômica contemporânea, uma vez que parte significativa do que é classificado como lixo é descartado, provocando os danos descritos anteriormente. Uma das soluções para os RSUs pode ser a reciclagem, que vem gerar lucro, renda e importantes e positivos efeitos ambientais e sociais para as cidades. Quanto a isso, também é importante destacar que o reuso e a reciclagem representam a diminuição de demanda sobre recursos naturais que poderiam ser poupados e otimizados. Todavia, apesar da relevância do tema, o que se observa é a ausência de práticas sistemáticas e consistentes de coleta seletiva, o que gera significativos impactos econômicos negativos.

Desta forma, é acertado dizer que o lixo em áreas urbanas converte-se em um problema com graves implicações sobre a saúde pública, para infraestrutura e a qualidade de vida nas cidades, para a economia e, agregando todos esses fatores, um importante e intenso problema ambiental, que demanda soluções rápidas, precisas, eficientes, sustentáveis e socialmente justas.

Para dimensionar, em linhas gerais, o quadro apresentado anteriormente, cabe considerar que segundo o Panorama dos Resíduos Sólidos no Brasil (2016), a geração brasileira anual nacional foi estimada em 71 milhões de toneladas. Esses dejetos têm origem nas 
mais variadas atividades humanas. Entretanto, quando comparado a outros países, a produção brasileira de resíduos sólidos não apresenta índices alarmantes. Produz-se no país em torno de 1,07 kg.hab-1.dia-1 (ABRELPE, 2015) o que coloca o Brasil, em termos absolutos, em situação mais vantajosa do que a maioria dos países desenvolvidos.

Ainda que o volume gerado de resíduos não seja 0 aspecto mais impactante, o manejo inadequado ou mesmo inexistente, causado por deficiências de gestão dos municípios são responsáveis pela intensificação dos problemas ambientais, sociais e de saúde pública. A maior parte das cidades brasileiras, quando apresentam um serviço de coleta convencional, não prevê a segregação dos resíduos na fonte, não prioriza a coleta seletiva e nem a reciclagem, ainda que exista no país legislação específica estabelecendo a obrigatoriedade de políticas públicas de coleta e reciclagem de resíduos sólidos urbanos. A ABRELPE aponta que somente $3 \%$ de todo o volume produzido no Brasil é reciclado ou reaproveitado (ABRELPE, 2014).

Agravando ainda mais a cena descrita acima, dados do CEMPRE (2016) indicam que a coleta seletiva $\mathrm{e}$ a reciclagem são incipientes e que apenas 18\% dos municípios brasileiros dispõem da infraestrutura e planejamento necessários para oferecer o serviço de coleta seletiva.

Assim, a falta de cumprimento das legislações específicas e, consequentemente, a não disponibilização de serviços e políticas públicas intensifica os efeitos negativos já expostos e compromete um amplo conjunto de atividades que poderiam reverter os problemas ambientais gerados atualmente pelos RSUs, otimizar o uso de recursos naturais e gerar renda para parcelas da população urbana, principalmente aquelas que se encontram em situação de extrema pobreza e vulnerabilidade.
Considerando o exposto acima, o presente artigo tem o objetivo de analisar a implantação de programa de coleta seletiva e reciclagem na Cidade de Palmas, capital do Tocantins. 0 foco central da abordagem está direcionado para o processo de formulação e efetivação do Programa Coleta Palmas, sua repercussão para as associações e cooperativas de catadores e seus resultados iniciais, uma vez que se trata de política recente, iniciada em 2017.

\section{Metodologia}

Pela natureza do tema aqui investigado, pode-se classificar a presente pesquisa como descritiva, visando a uma maior compreensão dos elementos que abrangem as tentativas e o atual estágio de implantação da coleta seletiva em Palmas. Quanto ao procedimento de coleta de dados, a pesquisa se classifica como qualitativa, pois a compreensão do fenômeno social aqui investigado se dá a partir da investigação dos elementos subjetivos atrelados ao tema e da compreensão dos contextos sociais e políticos em que se insere.

Em termos práticos a investigação foi iniciada com uma revisão bibliográfica, etapa em que se buscou sistematizar as abordagens já realizadas sobre o tema, visando, basicamente, a compreender os modelos teóricos já propostos em estudos similares e avaliar sua adequação ao caso do Programa Coleta Palmas.

Já a pesquisa documental, fase seguinte da investigação, foi feita por meio da análise de documentos relacionados à gestão, geração, manejo e disposição final dos resíduos sólidos urbanos. Assim, buscou-se dados préexistentes ao objeto de estudo, pesquisado nos órgãos municipais responsáveis pelo gerenciamento destes, como a Fundação do Meio Ambienta (FMA), Secretaria Municipal de Meio Ambiente e Desenvolvimento Urbano 
(SEMDU), Secretaria Municipal de Infraestrutura e Serviços Públicos (SEISP), o Plano Municipal de Saneamento Básico (Palmas, 2014), além da leitura e interpretação dos documentos legislativos nas esferas federal, estadual e municipal.

Neste item enquadra-se o projeto físico do programa piloto de implantação do Coleta Palmas, caracterizando as ações do poder público quanto aos resíduos sólidos urbanos recicláveis. Porém, esclarece-se que foi conseguido somente alguns rascunhos do projeto, $e$ mails e mensagens trocadas com o órgão responsável pela implantação do programa, a Fundação do Meio Ambiente de Palmas (FMA).

Em paralelo à pesquisa documental, foram iniciadas as pesquisas de campo. Após definir os sujeitos ou corpus da pesquisa, buscou-se a sistematização de dados sobre esses autores. Em termos práticos, foram realizadas visitas de campo aos órgãos públicos envolvidos na política e, de forma mais intensa e detalhada, às associações e organizações de catadores do Município de Palmas. Os dados produzidos nessa etapa permitiram a análise e interpretação das características e atuação dos envolvidos a respeito dos fenômenos que abrangem os grupos e os atores sociais envolvidos nas tentativas de implantação da coleta seletiva na capital do Estado do Tocantins, considerando os seus aspectos de relevância e envolvimento.

Em fevereiro de 2018 foi feita a primeira visita às associações e à cooperativa, visando estabelecer contato com os representantes em cada entidade participante do Programa Coleta Palmas, capaz de descrever a trajetória da implantação no programa piloto de coleta seletiva e suas contribuições relacionadas à atividade.

A técnica utilizada nas visitas de campo com os representantes das entidades foi a de entrevista narrativa. Atendendo às recomendações de Bauer e Gaskell (2002) para a entrevista qualitativa deve ser realizada uma pergunta geradora de narrativa, esperando que o entrevistado relate uma história improvisada ligada ao tema de estudo. No caso, foi utilizado o seguinte questionamento: Como está sendo a participação na implantação do programa piloto Coleta Palmas?

A pesquisa social apoia-se em dados que resultam da construção dos processos de comunicação. 0 interesse está na maneira como as pessoas, espontaneamente, se expressam e falam sobre o que é importante para elas, como elas pensam sobre suas ações e as dos outros sobre o tema em estudo (Bauer e Gaskell, 2002, p. 20).

Formando, a partir disso, as conclusões deste artigo, caracterizando a implantação do programa piloto Coleta Palmas com relação aos resíduos sólidos urbanos recicláveis por meio de ganhos socioambientais e políticos econômicos.

\section{Resultados e discussão}

Não há como negar a importância da reciclagem por meio da coleta seletiva, tendo em vista os fatores citados anteriormente, evidenciando-se, ainda, o esgotamento dos recursos naturais, a sobrecarga dos aterros sanitários, a poluição e os problemas causados à saúde pública quando ocorre a destinação ambientalmente inadequada dos resíduos sólidos urbanos (Caneloi, 2011).

De acordo com a norma ABNT NBR 10004/2004 (ABNT, 2004), a classificação para os resíduos sólidos urbanos recicláveis é Resíduos Classe II B - Inertes com a seguinte definição:

Quaisquer resíduos que, quando amostrados de uma forma representativa, segundo a ABNT NBR 10007, submetidos a um contato dinâmico e estático com água destilada ou desionizada, à temperatura ambiente, conforme ABNT NBR 10006, não tiverem nenhum de seus constituintes solubilizados a concentrações superiores aos padrões de potabi- 
lidade de água, excetuando-se aspecto, cor, turbidez, dureza e sabor (ABNT, 2004).

Portanto, a reciclagem possibilita o tratamento e recuperação destes, realizados por meio do tratamento mecânico, onde os processos físicos praticados nas usinas de triagem podem alterar o tamanho dos materiais facilitando sua comercialização como insumos, ou seja, matéria prima secundária para processos industriais.

Segundo a Política Nacional dos Resíduos Sólidos (PNRS), o serviço de coleta seletiva caracteriza-se como o conjunto de procedimentos referentes ao recolhimento de resíduos recicláveis e/ou de resíduos orgânicos compostáveis (PNRS, 2010) que tenham sido previamente separados dos demais resíduos considerados não reaproveitáveis, nos próprios locais em que tenha ocorrido sua geração.

A Pesquisa Nacional de Saneamento Básico realizada pelo Instituto Brasileiro de Geografia e Estatística (IBGE) (2000) indicou na Tabela 110, como dado nacional parcial, a quantidade diária de lixo coletado, por unidade de destino final nas grandes regiões, unidades da federação, regiões metropolitanas e municípios das capitais e divulgou uma produção diária de 228.413 mil toneladas.

Com relação aos dados do Município de Palmas, o Censo do IBGE de 2010 apontou uma população urbana de 217 mil habitantes e uma população estimada para o ano 2016 de 280 mil habitantes (IBGE, 2010).

Segundo o diagnóstico situacional do sistema de limpeza urbana e manejo de resíduos sólidos que compõe o Plano Municipal de Saneamento Básico de Palmas/TO (PMSB), anexo IV, ao Decreto no 700/2014, evidenciou-se uma média de geração diária de resíduos sólidos urbanos de 181.406,25 kg e per capita de $0,78 \mathrm{~kg}^{1}{ }^{1} \cdot \mathrm{hab}^{-1} \cdot \mathrm{dia}^{-1}$ (Palmas, 2014).

A composição gravimétrica realizada para a formulação do Plano
Municipal de Saneamento Básico de Palmas, que trata sobre os resíduos sólidos urbanos (RSU) permitiu caracterizar a tipologia e a quantificação concluindo que, aproximadamente, $48 \%$ são considerados materiais possíveis de reciclagem (Palmas, 2014).

Pode-se observar, portanto, que “o valor estimado de geração de resíduos sólidos no município de Palmas está dentro do valor de referência que é de 0,50 a 0,80 kg- ${ }^{1} \cdot$ hab- $^{1} \cdot$ dia- $^{1}$ para municípios com população entre $30 \mathrm{mil}$ e 500 mil habitantes, classificados como cidades médias, onde se enquadra o município estudado" (Palmas, 2014, p. 115).

Em Palmas, a coleta convencional dos resíduos sólidos urbanos abrange $100 \%$ das áreas regularizadas do município, sendo elas as áreas dentro do perímetro urbano e áreas urbanas isoladas. 0 volume coletado é direcionado ao aterro sanitário municipal, que teve seu início de operação no ano de 2001, após o encerramento do antigo aterro controlado. 0 espaço é operado pela prefeitura municipal com área total de aproximadamente 96 hectares, de propriedade do Instituto Nacional de Colonização e Reforma Agrária (INCRA), cedido para a prefeitura a uma distância de $26 \mathrm{~km}$ do centro da cidade (Palmas, 2009).

Vale ressaltar que, apesar da disposição final dos resíduos sólidos urbanos do município quando recolhidos ser o aterro sanitário, ou seja, uma obra de engenharia que dispõe os resíduos sólidos urbanos adequados ambientalmente, contendo técnicas para a mitigação dos impactos negativos sobre o meio ambiente e a saúde pública, a implantação da coleta seletiva e reciclagem tem muitos ganhos ambientais, sociais e econômicos.

No Plano Estadual de Resíduos Sólidos (Tocantins, 2017) importante documento relativo aos resíduos sólidos urbanos do Estado do Tocantins realizado por meio de um diagnóstico que apontou as deficiências e potencialidades 
relacionadas ao manejo, conhece-se a realidade de produção e destinação nos 139 municípios que compõem o estado e o Plano reforça que "os principais polos geradores de RSU no estado são: Palmas, Araguaína e Gurupi respectivamente, devido à grande concentração populacional e às atividades econômicas nestes centros urbanos, sendo estes municípios geradores de 66\% dos resíduos secos de todo o Estado" (PERS, 2016, p. 15).

Demonstrando a potencialidade para a implantação de um programa de coleta seletiva na capital, devendo-se incorporar, nas políticas públicas, diretrizes estabelecidas no Plano Nacional de Resíduos Sólidos (PNRS) como o apoio às cooperativas de catadores de materiais recicláveis além da redução gradativa da produção de resíduos sólidos urbanos.

Entre os marcos legais mais recentes para o alcance destas metas, merece destaque a Lei no $12.305 / 2010$, que institui a Política Nacional de Resíduos Sólidos (Brasil, 2010). Esta legislação determinou que os estados e os municípios elaborassem seu Plano Municipal de Saneamento Básico até o ano de 2014, melhorando as condições de salubridade ambiental, relacionadas com a correta gestão e gerenciamento do sistema e dos serviços de limpeza urbana e manejo de resíduos sólidos. Estabeleceu, ainda, que fosse implantada a coleta seletiva com a separação dos resíduos recicláveis dos rejeitos e seu encaminhamento. Tal ação deve se dar para as centrais ou galpões de triagem para posterior comercialização com as indústrias que utilizam estes materiais na fabricação de novos produtos.

A Política Nacional de Resíduos Sólidos (PNRS) levou dezenove anos tramitando no Congresso Nacional. Este longo período de debate revela o conjunto de tensões e conflitos de interesses nela envolvidos, que precisaram ser "negociados" para haver a sua promulgação pela Lei $\mathrm{n}^{\mathbf{0}}$ 12.305/2010 (Brasil, 2010).
A PNRS, Lei no 12.305/2010, regulamentada pelo Decreto no 7.404/2010 (Brasil, 2010), estabelece o novo marco regulatório para a área de resíduos sólidos, assumindo como um dos princípios básicos “[...] o reconhecimento do resíduo sólido reutilizável e reciclável como um bem econômico e de valor social, gerador de trabalho e renda e promotor de cidadania" (Brasil, 2010, art. 6, item VIII).

A referida Lei no 12.305/2010 prioriza, em diversos artigos, como os arts. 18, inciso II, 19, inciso XI, e 42, inciso III, a participação na coleta seletiva dos catadores de materiais recicláveis por meio de grupos formados por pessoas físicas de baixa renda (Brasil, 2010).

Outro aspecto importante a se destacar é o número destes catadores, que, segundo o relatório da Situação Social dos Catadores de Material Reciclável e Reutilizável do Instituto de Pesquisa Econômica Aplicada (IPEA) (2013), tinha-se, à época, próximo a 600 mil pessoas que se declararam catadores como sendo sua principal ocupação no Brasil.

Concordando com este valor o Cataforte/RS (2013) ainda especifica que entre 40 e 60 mil, ou seja, somente $10 \%$ do total, participam de organizações coletivas, estimando ao menos 1.100 organizações no Brasil. As regiões Sul e Sudeste concentram a maior parte de catadores e de organizações. Na região Norte onde se localiza o município de Palmas/TO, locus desta pesquisa, encontram-se quase 22 mil destes representando, 5,6\% do total.

Ainda segundo o estudo do IPEA (2013) o percentual de catadores que residem em áreas urbanas em todo o país chega a 93,3\%, caracterizando a atividade de coleta de material reciclável como de natureza essencialmente urbana. A atividade se dá por meio de associação, cooperativa ou mesmo catação individual para posterior venda.

Com relação à coleta seletiva em Palmas, oito anos antes da criação da 
PNRS, instrumento que formalizou o interesse da União em relação ao tema e estabeleceu diretrizes relativas à gestão integrada e ao gerenciamento dos resíduos sólidos, Lei $\mathrm{n}$ ํ 12.305/2010, foi criada a Lei Municipal no 1.165, de 11 de dezembro 2002, específica para a implantação da coleta seletiva de lixo no município (Palmas, 2002).

Tal Lei determina ao Poder Executivo promover o aproveitamento do lixo coletado na cidade e nos distritos, além de fortalecer cooperativas, associações e outras entidades do terceiro setor.

Posteriormente, o projeto de Lei Complementar no 14/2006, que dispõe sobre a política urbana e sobre o Plano Diretor Participativo no Município de Palmas, em conformidade com o Estatuto da Cidade, instituído pela Lei $\mathrm{n}^{\mathrm{o}}$ $10.257 / 2001$, em seu art. 46, esclarece que o saneamento ambiental contemplará o sistema de infraestrutura de coleta seletiva de resíduos sólidos.

No entanto, apenas em 2011 foi realizada uma ação experimental, por meio do Decreto Municipal ${ }^{\circ} 227$, de 14 de julho de 2011, que implantou a coleta seletiva de lixo nas escolas municipais e em instituições públicas e privadas que se comprometessem a fazer a separação dos materiais e duas quadras residenciais, a 404 e 904 sul, com o intuito de obter informações pela experiência concreta, dando embasamento e suporte para uma futura expansão do serviço de coleta seletiva na cidade (PSBM, 2014).

\section{o Coleta Palmas}

O Programa Coleta Palmas, lançado pela prefeitura municipal em maio de 2017, é um programa piloto de coleta seletiva. Conta com a parceria de duas associações e uma cooperativa, consideradas o elo inicial no processo de reciclagem, pois atuam desde a coleta até a comercialização dos materiais.

São estas: Associação de Catadores e Catadoras de Materiais
Recicláveis da Região Centro Norte de Palmas (ASCAMPA); Reciclo Palmas e a Cooperativa de Catadores de Materiais Recicláveis do Tocantins (COOPERAN), localizadas em Palmas/TO e, nas sedes destas unidades, são realizadas a triagem, compactação e posterior comercialização desses insumos para indústrias do Tocantins e Goiás.

O Programa Coleta Palmas está sendo realizado por meio de Pontos de Entrega Voluntária (PEV's) e configurase como fonte de abastecimento do mercado da reciclagem, por meio da contribuição da população que se desloca até um ponto e deposita nos coletores os resíduos que foram previamente separados, acondicionando-os, adequadamente, de acordo com a descrição do que cada um recebe.

Este método apresenta vantagens econômicas de investimento se comparado a outros métodos, pois possui facilidade na coleta, reduzindo os percursos percorridos pelos caminhões comparados a um sistema porta a porta, pois transfere parte dos custos de transporte para os cidadãos que levam seus resíduos até os pontos (Dourado, 2017).

Já alguns aspectos negativos são: as associações e cooperativas locais precisam esperar pela implantação e ampliação do número de pontos pela prefeitura ou órgãos responsáveis para beneficiar-se deste sistema; é necessário o monitoramento dos pontos para evitar o vandalismo e para que não sejam depositados rejeitos, contaminando os materiais que podem ser reciclados; além da necessidade da voluntariedade dos cidadãos em participar depositando os materiais nos contêineres. Outra questão importante é a dimensão destes recipientes, pois, se não forem bem dimensionados a capacidade dos coletores versus a frequência de coleta o sistema acaba gerando o acúmulo de lixo no exterior dos mesmos, causando má impressão exigindo manutenção e limpeza (Alvarenga, 2015). 
As cores usadas para identificar os recipientes de descarte dos resíduos sólidos urbanos no Programa Coleta Palmas a serem reciclados são azul (para papéis), vermelho (para plásticos), amarelo (para metais) de acordo com a Resolução CONAMA no 275/2001, que estabelece o código de cores para os diferentes tipos de resíduos a ser adotado nos coletores de coleta seletiva (Brasil, 2001).

Em Palmas, não existe coleta seletiva de vidro, que é utilizada a cor verde (para vidros), pois a indústria mais próxima que poderia comprar os materiais fica a $1.700 \mathrm{~km}$ de distância da capital Palmas. Deixando dúvidas quanto à efetividade ambiental do programa, pois não deveriam se sobressair às questões econômicas de uma ação socioambiental com tamanha importância.

0 vidro, se reciclado, pode substituir totalmente o produto virgem sem perda da qualidade, porém, como é comercializado estilhaçado exige equipamentos e cuidados específicos no processo e no manuseio, devido o perigo de cortes e ferimentos. Outro fator importante da reciclagem de vidro é o peso para transportá-lo e o seu baixo valor de mercado, fazendo com que muitas associações e cooperativas não trabalhem com este material. No entanto, durante o levantamento nos PEV's do programa Coleta Palmas, por falta de informação, a comunidade acaba deixando vidros, conforme foto a seguir.

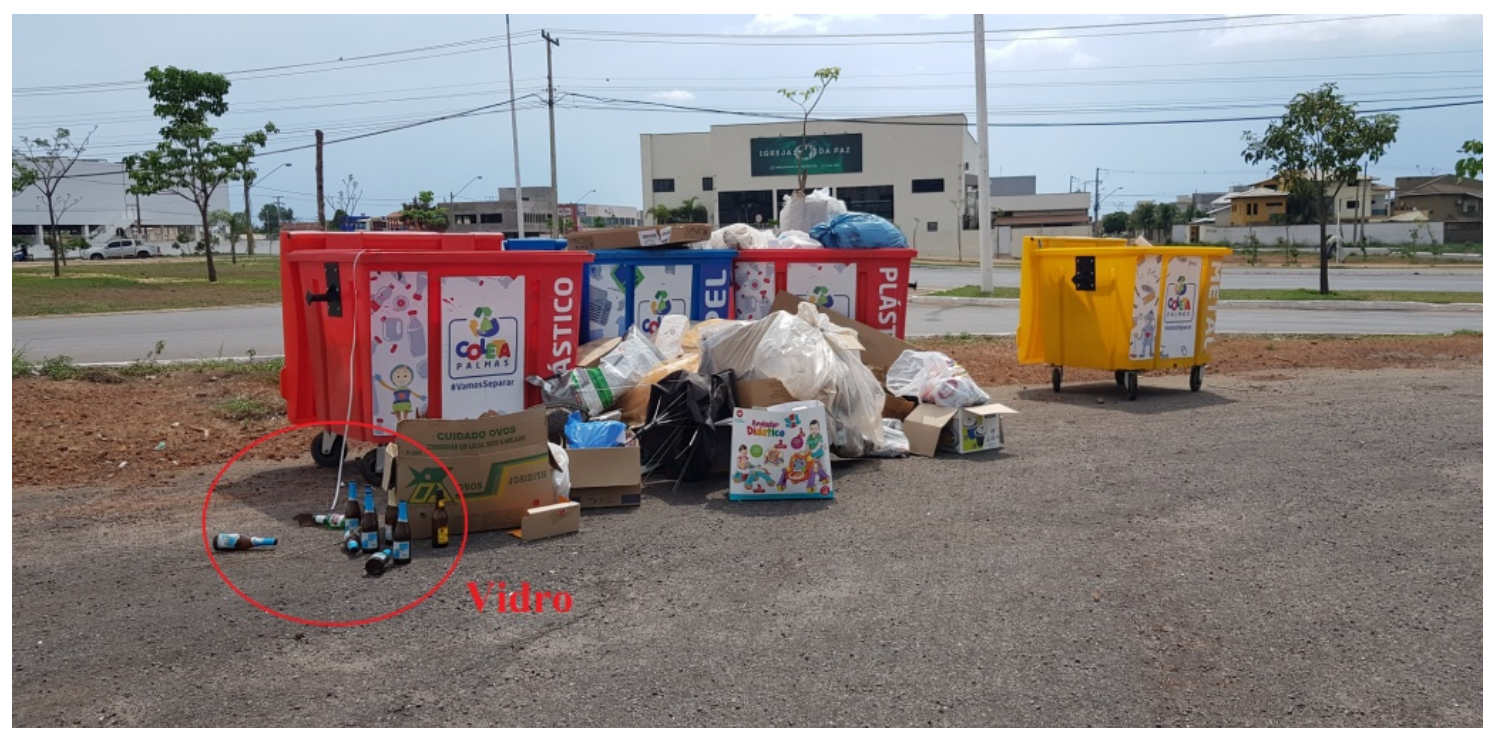

Figura 1. Vidro nos coletores do Coleta Palmas, 2018.

Outro fator importante é que a separação dos resíduos gerados nos coletores coloridos pode se tornar complexa para a comunidade, pois os produtos consumidos no dia a dia utilizam grandes diversidades de materiais em sua composição, dificultando a distinção na hora da categorização nos PEV's.
Outro aspecto a ressaltar é que cabe ao local ou município, com a coleta seletiva implantada, adotar somente as padronagens de cores de coletores dos materiais que possuem interessados em reciclar, reutilizar, vender ou comprar os resíduos, facilitando a distinção pela comunidade ao invés de adotar todas as cores estabelecidas pelo CONAMA $\mathrm{n}^{-}$ 275/2001, como é feito em Palmas. 
O programa piloto do Coleta Palmas tem como proposta reduzir, gradualmente, de acordo com as metas traçadas no PMSB, 2014, o descarte de materiais recicláveis no aterro sanitário, podendo, assim, aumentar a sua vida útil, envolver as organizações de catadores de materiais recicláveis, consolidando Palmas como um município ativo em práticas sócio-sustentáveis, contribuindo, por meio de sua atividade, com a preservação do meio ambiente e com a qualidade de vida.

\section{Considerações finais}

Considerando o tema abordado neste artigo sobre as legislações e os eventos que tentaram colocar em prática a coleta seletiva no Município de PalmasTO, percebe-se que estes não bastam para alterar as dinâmicas socioambientais urbanas relacionadas aos resíduos sólidos urbanos recicláveis. Pois, apesar da orientação que as leis fornecem, as mesmas não são executadas em sua totalidade, deixando as tentativas de coleta seletiva em Palmas sem um direcionamento, impedindo-a de acontecer efetivamente.

Uma delas é a Lei oㅜ 12.305/2010 que instituiu a Política Nacional dos Resíduos Sólidos (PNRS) e determinou que os municípios implantassem os aterros sanitários e iniciassem a coleta seletiva até o ano de 2014. Essa determinação fez com que, em alguns municípios brasileiros, os catadores deixassem de ter o contato direto com a destinação final dos resíduos sólidos urbanos nos lixões, fomentando a criação das associações e cooperativas de catadores no Brasil (Brasil, 2010).

Com a publicação desta Lei também foi estabelecido que deve haver a contratação de associações e cooperativas de catadores de materiais recicláveis sem a necessidade de licitação, por parte do titular dos serviços públicos de limpeza urbana e manejo de resíduos sólidos para a efetivação da coleta seletiva. Porém, em Palmas/TO estas associações e a cooperativa não foram contratadas para a realização deste serviço, somente foi feito uma parceria.

As associações ASCAMPA e a RECICLO PALMAS foram criadas em 2005 e a cooperativa COOPERAM foi criada em 2004. São parceiras do Programa Coleta Palmas mas, durante as visitas de campo para a realização desta pesquisa, percebeu-se que é necessário ter um melhor diálogo com estas organizações, pois as mesmas argumentam que não recebem nada em troca pelo trabalho executado e possuem muitas restrições financeiras para conseguir contribuir com o programa. Mesmo porque, não são eles que devem investir no programa e sim o poder público, dando-lhes melhores condições de trabalho ou ainda contratando-os para dar a correta destinação aos resíduos sólidos urbanos recicláveis conforme a PNRS.

Percebeu-se, durante a pesquisa, que as três participantes do Programa Coleta Palmas carecem de muitas coisas como, a ASCAMPA e a Reciclo Palmas precisam de um lugar regularizado e apto a receber a atividade, pois a ASCAMPA encontra-se ao lado de uma escola pública municipal em um terreno cedido pela prefeitura e a Reciclo Palmas trabalha em um pequeno terreno emprestado pelo vizinho ao lado da residência do representante da instituição.

Também não possuem coberturas fixas suficientes para executar o trabalho protegidos das intempéries ou mesmo para zelar pelos equipamentos elétricos como as prensas que não podem pegar chuva. Faltando, inclusive, banheiros para os associados e cooperativados usarem durante o trabalho. 


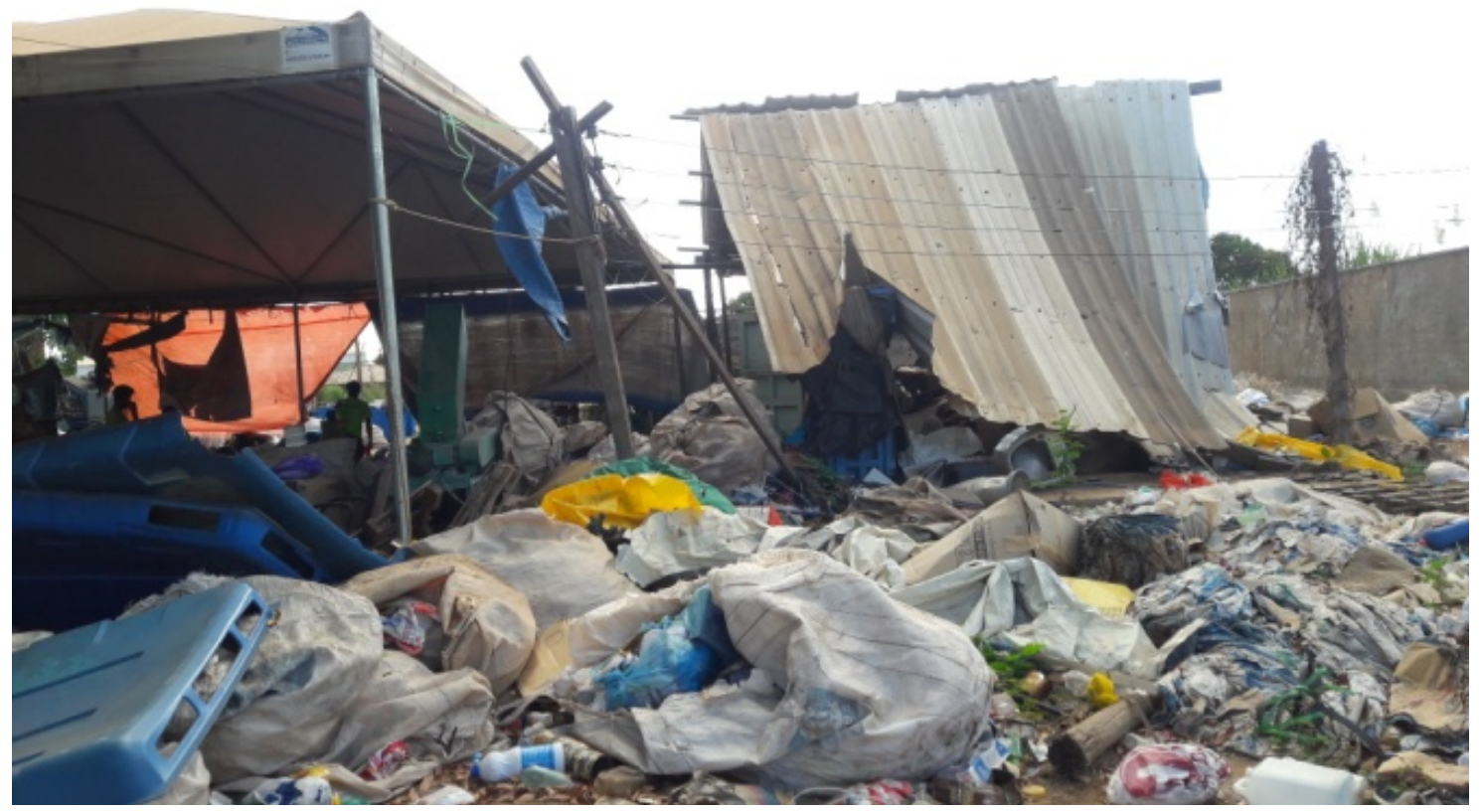

Figura 2. Improvisação da cobertura na ASCAMPA.

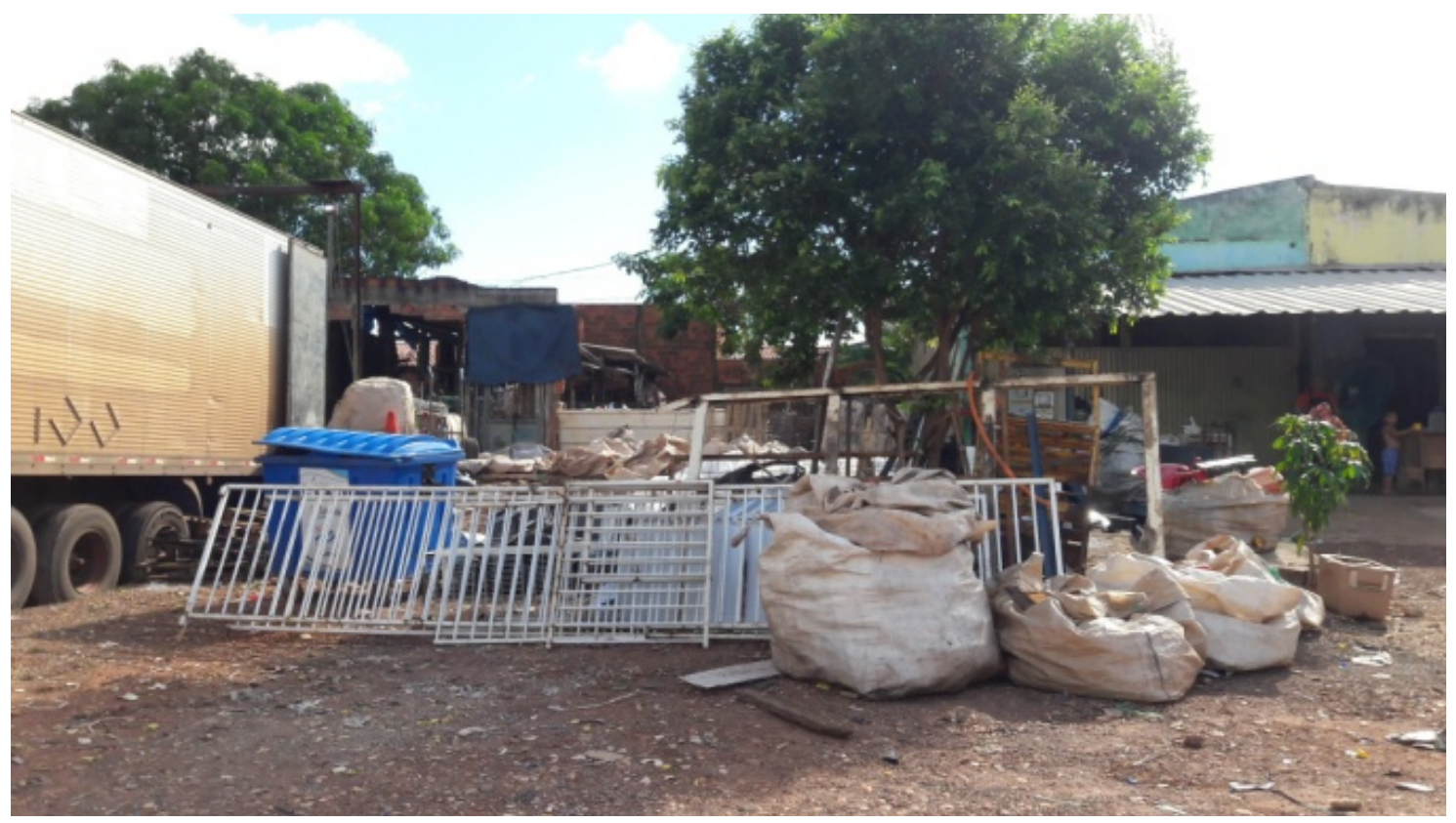

Figura 3. Falta de cobertura na Reciclo Palmas.

As associações e a cooperativa não possuem ajuda de custo para o recolhimento dos materiais nos PEV's, o que gera muitos gastos com o diesel e manutenção dos caminhões, pois necessitam rodar grande parte da cidade onde os PEV's estão instalados. Também mencionam que, apesar das campanhas da FMA em fazer a conscientização nas escolas públicas e outros eventos que acontecem na cidade, a comunidade dispõe nos PEV's muitos materiais heterogêneos, ou seja, misto e variado com difícil classificação. Esclarecendo 
que os produtos que apresentam mais de um material em sua formação não servem para as organizações de Palmas, pois se perde muito tempo para separar os diferentes tipos de materiais.

Portanto, não são todos os materiais que são recicláveis para o caso de Palmas, os materiais que interessam às organizações são os que possuem comprador, isto é, sejam comercializáveis para as indústrias que utilizam estes como insumos para a fabricação de novos produtos.

É importante ressaltar que a Lei no $12.305 / 2010$ fundamentou os documentos do Plano Municipal de Saneamento Básico (Palma, 2014) e o Plano Estadual de Resíduos Sólidos do Tocantins (2017), ambos feitos para o Tocantins. Em conformidade com a lei, os planos tratam dos resíduos sólidos urbanos e expõem a necessidade de implantar a coleta seletiva, incentivando a reciclagem, incluindo socialmente os catadores das associações e cooperativas, além de prescrever a capacitação continuada destes trabalhadores, fomentar a educação ambiental nas escolas e a conscientização da sociedade em geral, pois é da população que vêm os resíduos que darão efetividade às políticas públicas de coleta seletiva.

Percebeu-se em um desses documentos que um fator limitante é que o atual Programa de Coleta Seletiva, o Coleta Palmas, objeto de estudo deste artigo, é um programa sem ter Lei vinculada. Isso acontece porque, em 2014, o Plano Municipal de Saneamento Básico - Vol. IV que trata dos resíduos sólidos urbanos é um anexo do Decreto no 700, ou seja, o PMGIRS deveria ter sido lançado como Lei e abaixo dele viriam os Decretos normatizando os programas. Esse fato agravou a dificuldade em se fazer cumprir a coleta seletiva.

Esta pesquisa evidenciou que os RSURs podem ser uma grande fonte de renda visto que identificou-se outras empresas em Palmas que não são associações nem cooperativas, não fazem parte do atual programa de coleta seletiva, mas funcionam por meio do beneficiamento e comercialização dos materiais recicláveis. Estas possuem proprietário e funcionários com carteira de trabalho assinada, além de possuir caminhão ou veículo com carretinha, terreno alugado e murado com melhor estrutura para atender os colaboradores e executar o trabalho.

Ressaltando que, as ações do poder público quanto à gestão compartilhada que a PNRS propõem devem ser: apresentar planos para o armazenamento e acondicionamento correto dos resíduos sólidos urbanos; integrar os catadores; se responsabilizar pelos serviços de limpeza urbana e manejo de resíduos domiciliares. Já a sociedade precisa se responsabilizar por acondicionar adequadamente os resíduos e disponibilizar corretamente estes para a coleta. As empresas precisam se responsabilizar pelos próprios resíduos gerados em seus processos produtivos e pela logística reversa (Leme et.al., 2012).

Apesar da previsão legal, a participação da sociedade na coleta seletiva, quando existe, é voluntária na maioria dos municípios, assim como em Palmas e depende, fundamentalmente, da sensibilização e da participação dos cidadãos, empresas e instituições para dar certo. Estas ações podem ser feitas por meio da informação com intervenções educativas diversificadas, para mobilizar a comunidade, entre estas: palestras, oficinas e cursos de forma contínua fortalecendo os vínculos entre as entidades e a comunidade, multiplicando os processos para transformar a realidade local. Porém, as entidades participantes sinalizam que não existe divulgação nas mídias locais.

As dificuldades em se fazer cumprir e aplicar as leis e as políticas públicas são potencializadas pela falta de uma base sólida de dados ambientais e sociais; recursos financeiros escassos; carência de recursos humanos necessários à prática de gestão ambiental 
em todos os níveis, descartando, muitas vezes, a vulnerabilidade aos interesses econômicos e político-partidários.

Com relação à política pública do Programa Coleta Palmas, fica evidente que a prefeitura precisa se esforçar e investir recursos financeiros para a real implantação, pois foram previstos inicialmente vinte e oito PEV's, mas o programa começou com vinte e três. No decorrer do ano de 2018, apresentou uma redução de sete PEV's, apesar de firmarem o compromisso com o aumento dos pontos para cinquenta e cinco até o fim do ano de 2018, porém, isto não ocorreu. Essa situação, de redução dos PEV's, faz com que a população fique desatualizada com relação aos locais onde estão os pontos para depositar os materiais e desacreditada na efetividade e força desta nova tentativa de colocar em prática a coleta seletiva.

\section{Conflito de interesses}

Os autores declaram não haver conflito de interesses.

\section{Referências}

ABNT - Associação Brasileira de Normas Técnicas. ABNT NBR 10004:2004: Resíduos sólidos - Classificação. 2. ed. Rio de Janeiro: ABNT, 2004.

ABRELPE - Associação Brasileira de Empresas de Limpeza Pública e Resíduos Especiais. Brasil é o quinto maior produtor mundial de resíduos sólidos e recicla apenas 3\% do que é descartado. São Paulo: ABRELPE, 2014.

ABRELPE - Associação Brasileira de Empresas de Limpeza Pública e Resíduos Especiais. Panorama dos Resíduos Sólidos no Brasil. São Paulo: ABRELPE, 2014.

ABRELPE - Associação Brasileira de Empresas de Limpeza Pública e Resíduos Especiais. Panorama dos Resíduos Sólidos no Brasil. São Paulo: ABRELPE, 2015.

ABRELPE - Associação Brasileira de Empresas de Limpeza Pública e Resíduos
Especiais. Panorama dos Resíduos Sólidos no Brasil. São Paulo: ABRELPE, 2016.

ABRELPE - Associação Brasileira de Empresas de Limpeza Pública e Resíduos Especiais. Panorama dos Resíduos Sólidos no Brasil. Edição especial 15 anos. São Paulo: ABRELPE, 2017.

Alvarenga, J. C. Gerenciamento de Resíduos Sólidos Urbanos: Uma análise da distribuição espacial dos pontos de entrega voluntária de material reciclável em Viçosa/MG. Revista Políticas Públicas \& Cidades, v. 2, p. 45-66, 2015.

Bauer, M. W.; Gaskell, G. Pesquisa qualitativa com texto, imagem e som: um manual prático. Petrópolis: Vozes, 2002.

Brasil. Decreto no $\mathbf{7 . 4 0 4}$, de 23 de dezembro de 2010. Regulamenta a Lei $n^{0}$ 12.305, de 2 de agosto de 2010, que institui a Política Nacional de Resíduos Sólidos, cria o Comitê Interministerial da Política Nacional de Resíduos Sólidos e o Comitê Orientador para a Implantação dos Sistemas de Logística Reversa, e dá outras providências. Disponível em: <http://www.planalto.gov.br/ccivil_03/ _ato2007-2010/2010/Decreto/D7404.htm>. Acesso em: 23 abr. 2019.

Brasil. Lei no 12.305 de 02 de agosto de 2010. Institui a Política Nacional de Resíduos Sólidos; altera a Lei $\mathrm{n}^{-}$9.605, de 12 de fevereiro de 1998; e dá outras providências. Disponível em: <http://www.planalto. gov.br/ccivil_03/_ato2007-2010/2010/lei/ 112305.htm>. Acesso em: 23 abr. 2019.

Brasil. Resolução CONAMA no 275 , de 25 de abril de 2001. Estabelece o código decores para os diferentes tipos de resíduos, a ser adotado na identificação de coletores e transportadores, bem como nas campanhas informativas para a coleta seletiva. Disponível em: <http://www2.mma.gov.br/ port/conama/legiabre.cfm?codlegi=273>.

Acesso em: 23 abr. 2019.

Caneloi, T. P. Reciclagem e políticas públicas: a questão da tributação dos materiais recicláveis e reciclados. São Paulo: USP, 2011. (Dissertação de mestrado).

CEMPRE - Compromisso Empresarial para Reciclagem. Pesquisa Ciclosoft, 2016: radiografando a coleta seletiva. Rio de Janeiro: CEMPRE, 2016. 
Dourado, D. G. Avaliação contingente da participação de moradores de Palmas/TO em um programa de coleta seletiva de resíduos sólidos domiciliares. Palmas: Universidade Federal do Tocantis, 2017. (Dissertação de mestrado).

Governo do Estado do Tocantins. Plano Estadual de Resíduos Sólidos do Estado do Tocantins. Palmas: Governo do Estado do Tocantins, 2016. (Produto 03 - Meta 02. Panorama dos Resíduos Sólidos no Estado).

IBGE - Instituto Brasileiro de Geografia e Estatística. Pesquisa Nacional de Saneamento Básico: Tabela 110. Rio de Janeiro: IBGE, 2000.

IPEA - Instituto de Pesquisa Econômica Aplicada. Os que sobrevivem do lixo. Instituto de Pesquisa Econômica Aplicada. Ano 10. Edição 77, 2013.

Leme, P. S.; Martins, J. L. G.; Brandão, D. Guia prático para minimização e gerenciamento de resíduos. São Carlos: USP Recicla, 2012.

Medeiros, J. B.; Tomasi, C. Comunicação científica: normas técnicas para redação científica. São Paulo: Atlas, 2008.

Palmas. Aterro Sanitário de Palmas é considerado modelo nacional. Palmas: PMP, 2009.
Palmas. Decreto no 700, de 15 de janeiro de 2014. Institui o Plano Municipal de Saneamento Básico - PMSB do Município de Palmas e adota outras providências. Disponível em: <https://legislativo.palmas. to.gov.br/media/leis/DECRETO\%20N\%C2\% BA\%20700-2014\%20de\%2015-01-

2014\%2017-14-56.pdf>. Acesso em: 23 abr. 2019.

Palmas. Lei Complementar no 14, de 07 de novembro de 2006. Dispõe sobre a política urbana do Município de Palmas. Palmas, 2006.

Palmas. Lei no 1.165, de dezembro de 2002. Institui a coleta seletiva de lixo no município de palmas e dá outras providências. Disponível em: <https://www.palmas.to.gov.br/media/doc/ arquivoservico/PMSB_Palmas_Volume_04_Re siduos_Solidos_Versao_Final.pdf>. Acesso em: 23 abr. 2019.

Tocantins. Plano Estadual de Resíduos Sólidos do Estado do Tocantins. Palmas: Governo do Estado do Tocantins, 2017.

Zeeland, A. (Org.). Cataforte/RS: fortalecimento do associativismo e cooperativismo dos catadores de materiais recicláveis. São Leopoldo: Oikos, 2013. 
Rev. Bras. Gest. Amb. Sustent., 2019, vol. 6, n. 14, p. 931-943. 